\title{
CYFRA 21-1 as a Predictive Marker for Non-small Cell Lung Cancer Treated with Pemetrexed-based Chemotherapy
}

\author{
KAZUKI SONE ${ }^{1}$, TETSUYA OGURI ${ }^{1}$, MAKOTO NAKAO ${ }^{2}$, YUSUKE KAGAWA ${ }^{2}$, RYOTA KUROWAKA ${ }^{2}$, \\ HIROMI FURUTA ${ }^{3}$, SATOSHI FUKUDA ${ }^{1}$, TAKEHIRO UEMURA ${ }^{1}$, OSAMU TAKAKUWA ${ }^{1}$, \\ YOSHIHIRO KANEMITSU ${ }^{1}$, HIROTSUGU OHKUBO ${ }^{1}$, MASAYA TAKEMURA ${ }^{1}$, KEN MAENO $^{1}$, \\ YUTAKA ITO $^{1}$, HIDEFUMI SATO ${ }^{2}$, HIDEKI MURAMATSU $^{2}$ and AKIO NIIMI ${ }^{1}$ \\ ${ }^{I}$ Department of Respiratory Medicine, Allergy and Clinical Immunology, \\ Nagoya City University Graduate School of Medical Sciences, Nagoya, Japan; \\ ${ }^{2}$ Department of Respiratory Medicine, Kainan Hospital Aichi Prefectural Welfare \\ Federation of Agricultural Cooperatives, Yatomi, Japan; \\ ${ }^{3}$ Department of Thoracic Oncology, Aichi Cancer Center Hospital, Nagoya, Japan
}

\begin{abstract}
Background: Pretreatment serum tumor marker levels predict outcome in non-small cell lung cancer (NSCLC). However, little is known about the clinical value of such measurements for patients treated with pemetrexed plus a platinum-derivative. Patients and Methods: We retrospectively screened 100 chemotherapy-naïve patients with advanced non-squamous NSCLC treated with pemetrexed plus a platinum-derivative in relation to the pretreatment level of cytokeratin 19 fragment (CYFRA 21-1) and carcinoembryonic antigen (CEA). Results: Sixty one patients with a high CYFRA 21-1 level had statistically shorter progression-free and overall survival than 39 patients with a normal CYFRA 21-1 level (median progression-free survival $=127$ days $v s .191$ days, respectively; $p=0.046 ;$ median overall survival $=360$ days $v$ s. 781 days, respectively, $p<0.001)$. Serum CEA level was not related to survival. Conclusion: Serum CYFRA 21-1 level is a predictive and prognostic marker in patients with NSCLC treated with pemetrexed plus a platinum-derivative.
\end{abstract}

Pemetrexed is one of the most widely used cytotoxic agents, and is especially effective for non-squamous non-small cell lung cancer (non-SqNSCLC) (1). In first-line studies, pemetrexed plus a platinum-derivative was better tolerated

Correspondence to: Tetsuya Oguri, Department of Respiratory Medicine, Allergy and Clinical Immunology, Nagoya City University Graduate School of Medical Sciences, 1 Kawasumi, Mizuho-cho, Mizuho-ku, Nagoya, Aichi, 467-8601, Japan. E-mail: t-oguri@med.nagoya-cu.ac.jp

Key Words: Cytokeratin 19 fragment, tumor marker, pemetrexed, non-squamous non-small cell lung cancer. and offered superior survival than conventional treatment (2, 3). Moreover, it was demonstrated that pemetrexed maintenance therapy prolonged overall survival (OS) and was well tolerated (4). Pemetrexed plus a platinumderivative is recommended as standard therapy for advanced non-SqNSCLC. However, clinical predictive markers for the therapeutic effect of pemetrexed-based chemotherapy have not been established.

It has been shown in meta-analysis that cytokeratin 19 fragment (CYFRA 21-1), which is usually used as a tumor marker of lung cancer, is a prognostic indicator of NSCLC $(5,6)$. Fiala et al. reported that the pretreatment serum level of CYFRA 21-1 and other tumor markers predict shorter OS in patients treated with pemetrexed-based chemotherapy (7). However, little is known about the predictive value of serum tumor markers for advanced patients with non-SqNSCLC treated with pemetrexed plus a platinum-derivative.

The aim of the present study was to analyze the predictive and prognostic value of the pretreatment serum level of CYFRA 21-1 and of carcinoembryonic antigen (CEA) in patients with advanced-stage non-SqNSCLC treated with pemetrexed plus a platinum-derivative in a first-line setting.

\section{Patients and Methods}

In this retrospective cohort study, we screened cases of chemotherapy-naïve patients with advanced non-SqNSCLC treated with pemetrexed plus a platinum derivative at Nagoya City University Hospital and the Kainan Hospital (Japan) between 2010 and 2015. Approval for the study was obtained from our Institutional Ethics Committee (no. 1301), and routine medical data were analyzed under complete anonymity. All patients had locally advanced (stage IIIB) or metastasized (stage IV) non-SqNSCLC. Patients received pemetrexed at a dose of $500 \mathrm{mg} / \mathrm{m}^{2}$ on day 1 and either cisplatin at a dose of $75 \mathrm{mg} / \mathrm{m}^{2}$ on day 1 or carboplatin at the 
area under the concentration-time curve (AUC) 6 on day 1 every 3 weeks. Induction treatment with platinum derivative was scheduled for up to 4-6 cycles, followed by maintenance pemetrexed monotherapy in patients with non-progressive disease. Addition of pemetrexed monotherapy was at the treating physician's discretion.

The serum CYFRA 21-1 and CEA levels were measured before the initial chemotherapy. The serum CYFRA 21-1 level was measured using a commercial electrochemiluminescence immunoassay on LUMIPULSE Presto II system (Fujirebio Inc., Tokyo, Japan) or Cobas 8000 system (Roche Diagnostics, Tokyo, Japan). The serum CEA level was measured using a commercial electrochemiluminescence immunoassay on HISCL-5000 system (Sysmex, Hyogo, Japan) or Cobas 8000 system (Roche Diagnostics). Measurements were made at laboratories in the two hospitals, using cut-off values of $3.5 \mathrm{ng} / \mathrm{ml}$ for CYFRA 21-1, and $5.0 \mathrm{ng} / \mathrm{ml}$ for CEA, which were the upper limit of normal values at the two hospitals.

Statistical analysis. The response rate (RR) was defined as the best overall response according to Response Evaluation Criteria In Solid Tumours (RECIST) (8). The disease control rate (DCR) was defined as the percentage of patients who did not have progressive disease. Survival was estimated using the Kaplan-Meier method. Progression-free survival (PFS) was measured from the date of the first course of initial chemotherapy to the date of first disease progression, of death, or of the last follow-up. OS was measured from the date of the first course of initial chemotherapy to the date of death or of the last follow-up. Differences in RR and DCR between groups were evaluated using Fisher's exact test. A log-rank test was performed to evaluate the significance of differences in PFS and OS between the groups. As a level of statistical significance, a value of $p=0.05$ was used. Univariate analyses were carried out by means of log-rank tests. Multivariate analysis using a Cox proportional hazards model was used to establish the association between the clinical variables and survivals, and $p=0.10$ was the significance level used for adding or deleting a covariable from the model. As the level of statistical significance in the model, $p=0.05$ was used. All statistical analyses were performed with EZR (Saitama Medical Center, Jichi Medical University, Saitama, Japan), which is a graphical user interface for $\mathrm{R}$ (The R Foundation for Statistical Computing, Vienna, Austria). More precisely, it is a modified version of $\mathrm{R}$ commander designed to add statistical functions frequently used in biostatistics (9).

\section{Results}

The study included 100 patients whose characteristics are shown in Table I. The median age was 67 years (range $=40-81$ years). Thirty-three patients (33\%) were female, and $25(25 \%)$ were never smokers. Most patients had adenocarcinoma, and most patients had stage IV disease. Ninety-eight patients (98\%) had a good performance status (PS) (0 or 1). Twenty-one patients $(21 \%)$ had epidermal growth factor receptor $(E G F R)$ mutation, and four patients $(4 \%)$ had anaplastic lymphoma kinase $(A L K)$ translocation; no patient had both gene mutations.

Sixty-one $(61 \%)$ patients had a serum CYFRA 21-1 level that was above the normal upper limit of $3.5 \mathrm{ng} / \mathrm{ml}$ before the initial chemotherapy. The serum CEA level was elevated $(>5.0 \mathrm{ng} / \mathrm{ml})$ in 89 patients before the initial chemotherapy.
Table I. Patient characteristics $(n=100)$.

\begin{tabular}{|c|c|}
\hline Characteristic & Value \\
\hline \multicolumn{2}{|l|}{ Age (years) } \\
\hline Median & 67 \\
\hline Range & $40-81$ \\
\hline \multicolumn{2}{|l|}{ Gender, $\mathrm{n}$} \\
\hline Male & 67 \\
\hline Female & 33 \\
\hline \multicolumn{2}{|l|}{ Smoking status, $\mathrm{n}$} \\
\hline Current or former smoker & 75 \\
\hline Never smoked & 25 \\
\hline \multicolumn{2}{|l|}{ Histological type, $\mathrm{n}$} \\
\hline Adenocarcinoma & 97 \\
\hline Large cell carcinoma & 3 \\
\hline \multicolumn{2}{|l|}{ Disease stage, $\mathrm{n}$} \\
\hline IIIB & 2 \\
\hline IV & 98 \\
\hline \multicolumn{2}{|l|}{ ECOG PS, $n$} \\
\hline $0-1$ & 97 \\
\hline 2 & 3 \\
\hline \multicolumn{2}{|l|}{ EGFR mutation status, $\mathrm{n}$} \\
\hline Positive & 21 \\
\hline Wild-type & 79 \\
\hline \multicolumn{2}{|l|}{ ALK translocation status, $n$} \\
\hline Positive & 4 \\
\hline Negative & 96 \\
\hline \multicolumn{2}{|l|}{ No. of prior systemic regimens, $n$} \\
\hline 0 & 88 \\
\hline 1 & 12 \\
\hline \multicolumn{2}{|l|}{ Type of prior systemic therapy, $n$} \\
\hline Platinum-based therapy & 0 \\
\hline EGFR tyrosine kinase inhibitor & 12 \\
\hline ALK inhibitor & 0 \\
\hline \multicolumn{2}{|l|}{ Regimen, $\mathrm{n}$} \\
\hline $\mathrm{CDDP}+\mathrm{PEM}$ & 35 \\
\hline $\mathrm{CBDCA}+\mathrm{PEM}$ & 65 \\
\hline \multicolumn{2}{|l|}{ No. of induction chemotherapy cycles } \\
\hline Median & 4 \\
\hline Range & $1-6$ \\
\hline \multicolumn{2}{|l|}{ Pemetrexed maintenance therapy, $\mathrm{n}$} \\
\hline Yes & 39 \\
\hline No & 61 \\
\hline \multicolumn{2}{|l|}{ CEA (ng/ml) } \\
\hline Median & 14.1 \\
\hline Range & $0.7-5235.5$ \\
\hline \multicolumn{2}{|l|}{ CYFRA 21-1 (ng/ml) } \\
\hline Median & 5.0 \\
\hline Range & $0.5-684.0$ \\
\hline
\end{tabular}

ECOG PS, Eastern Cooperative Oncology Group performance status; $E G F R$, epidermal growth facter receptor; $A L K$, anaplastic lymphoma kinase; CDDP, cisplatin; CBDCA, carboplatin; PEM, pemetrexed; CEA, carcinoembryonic antigen; CYFRA 21-1, cytokeratin 19 fragment.

At the time of analysis, the median follow-up was 426 days (range=24-1374 days). There was no difference in RR between patients with a high and those with a normal CYFRA 21-1 level (36.1\% vs. 33.3\%, $p=0.8323)$. Patients 

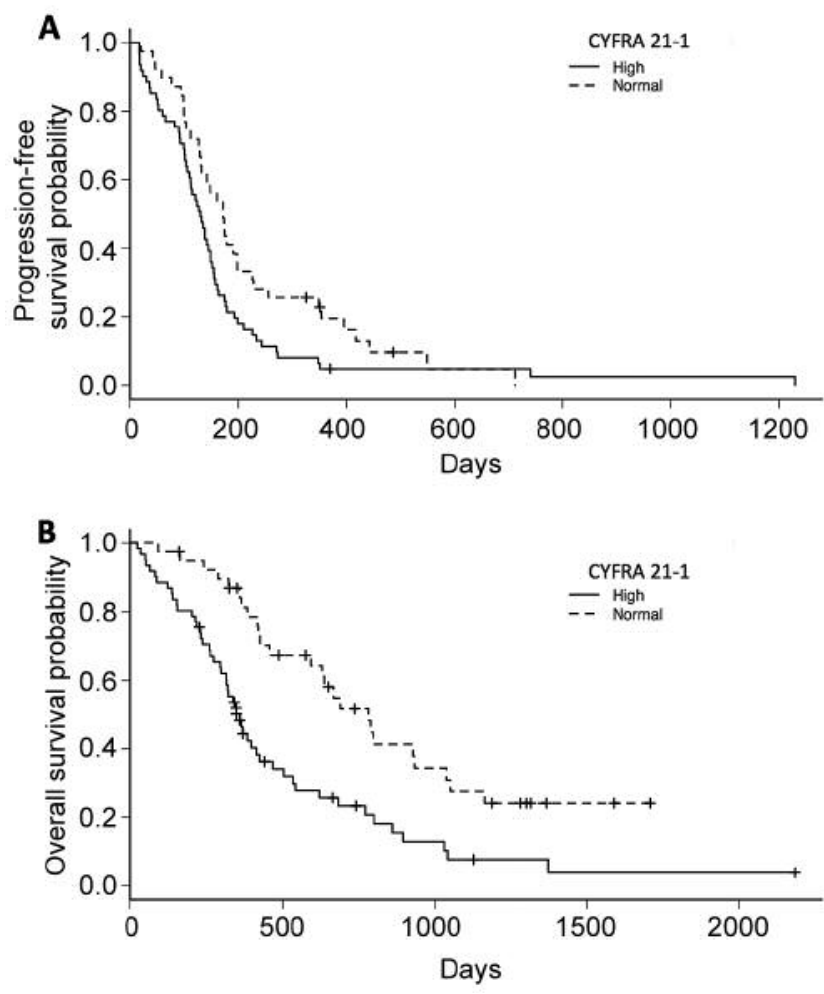

Figure 1. Kaplan-Meier survival curves of progression-free (A) and overall $(B)$ survival according to serum cytokeratin 19 fragment (CYFRA 21-1) level. The median PFS in patients with high and normal serum CYFRA 21-1 levels was 127 days [95\% confidence interval $(C I)=103-152$ days] and 191 days (95\% CI=103-349 days), respectively $(p=0.046)$. The median $O S$ in patients with high and normal levels of CYFRA 21-1 was 360 days (95\% CI=299-425 days) and 781 days (95\% $C I=457-1038$ days $)$, respectively $(p<0.001)$.

with a high CYFRA 21-1 level tended to have a lower DCR than patients with a normal CYFRA 21-1 level (77\% vs. $92.3 \%, p=0.0587)$. Patients with a high level of CYFRA 211 also experienced statistically shorter PFS compared with those with a normal level (log-rank $p=0.035)$, with a median PFS of 129 days [95\% confidence interval $(\mathrm{CI})=103-152$ days] vs. 172 days (95\% CI=103-349 days) respectively $(p=0.046)$ (Figure 1A). The median duration of PFS of patients with high and normal serum CEA levels was 149 days (95\% $\mathrm{CI}=129-172$ days) and 111 days $(95 \% \mathrm{CI}=99-158$ days), respectively ( $p=0.963$ ).

To determine potential predictive factors among clinical characteristics including the serum CYFRA 21-1 and CEA level in the patients with non-SqNSCLC treated with pemetrexed and platinum derivatives, we performed a univariate analysis on the clinical variables listed in Table II. Stage, histological type and performance status were excluded from the analysis because they were too one-sided. A high level of CYFRA 21-1 was statistically the only factor
Table II. Univariate analysis of survival by log-rank test.

\begin{tabular}{|c|c|c|c|c|c|}
\hline Factor & $\mathrm{n}$ & $\begin{array}{c}\text { Median } \\
\text { PFS } \\
\text { (days) }\end{array}$ & $p$-Value & $\begin{array}{c}\text { Median } \\
\text { OS } \\
\text { (days) }\end{array}$ & $p$-Value \\
\hline \multicolumn{6}{|l|}{ Age } \\
\hline$\geq 75$ Years & 87 & 134 & \multirow[t]{2}{*}{0.201} & 420 & \multirow[t]{2}{*}{0.380} \\
\hline$<75$ Years & 13 & 172 & & 503 & \\
\hline \multicolumn{6}{|l|}{ Gender } \\
\hline Male & 67 & 137 & \multirow[t]{2}{*}{0.894} & 426 & \multirow[t]{2}{*}{0.186} \\
\hline Female & 33 & 144 & & 468 & \\
\hline \multicolumn{6}{|l|}{ Smoking status } \\
\hline Never smoked & 25 & 137 & \multirow[t]{2}{*}{0.79} & 683 & \multirow[t]{2}{*}{0.017} \\
\hline Current or former smoker & 75 & 141 & & 420 & \\
\hline \multicolumn{6}{|l|}{ Driver mutation* } \\
\hline Yes & 25 & 148 & \multirow[t]{2}{*}{0.204} & 799 & \multirow[t]{2}{*}{0.018} \\
\hline No & 75 & 137 & & 414 & \\
\hline \multicolumn{6}{|l|}{ Pretreatment } \\
\hline Yes & 12 & 148 & \multirow[t]{2}{*}{0.503} & 347 & \multirow[t]{2}{*}{0.065} \\
\hline No & 88 & 134 & & 468 & \\
\hline \multicolumn{6}{|l|}{ Regimen } \\
\hline $\mathrm{CDDP}+\mathrm{PEM}$ & 35 & 128 & \multirow[t]{2}{*}{0.528} & 544 & \multirow[t]{2}{*}{0.754} \\
\hline CBDCA+PEM & 65 & 149 & & 385 & \\
\hline \multicolumn{6}{|l|}{ CYFRA 21-1 } \\
\hline$\leq 3.5 \mathrm{ng} / \mathrm{ml}$ & 39 & 172 & \multirow[t]{2}{*}{0.035} & 781 & \multirow[t]{2}{*}{$<0.001$} \\
\hline$>3.5 \mathrm{ng} / \mathrm{ml}$ & 61 & 129 & & 360 & \\
\hline \multicolumn{6}{|l|}{ CEA } \\
\hline$\leq 5.0 \mathrm{ng} / \mathrm{ml}$ & 25 & 111 & \multirow[t]{2}{*}{0.963} & 365 & \multirow[t]{2}{*}{0.664} \\
\hline$>5.0 \mathrm{ng} / \mathrm{ml}$ & 75 & 149 & & 468 & \\
\hline
\end{tabular}

PFS, Progression-free survival; OS, overall survival; CDDP, cisplatin; PEM, pemetrexed; CBDCA, carboplatin; CYFRA 21-1, cytokeratin 19 fragment; CEA, carcinoembryonic antigen. *Epidermal growth factor receptor mutation or anaplastic lymphoma kinase translocation.

with predictive efficacy $(p=0.035)$. As shown in Figure 1B, the median duration of OS for patients with high and normal levels of CYFRA 21-1 was 360 days (95\% CI=299-425 days) and 781 days (95\% CI=457-1038 days), respectively $(p<0.001)$. The median duration of OS of patients with high and normal serum CEA levels was 468 days $(95 \% \mathrm{CI}=370$ 668 days) and 365 days (95\% CI=290-771 days), respectively $(p=0.664)$.

Potential prognostic factors were subjected to a univariate survival analysis (Table II). Never-smoked status $(p=0.017)$, presence of driver mutations (EGFR mutation or $A L K$ translocation), and a normal serum CYFRA 21-1 level were associated with better OS. To determine independent prognostic factors, we performed multivariate analyses (Table III). Lack of driver mutation $(p<0.022)$, no pretreatment $(p=0.008)$ and a normal serum CYFRA 21-1 level $(p=0.007)$ were statistically independent prognostic factors for better OS. In the population without driver mutations, the median duration of OS in patients with a high 
Table III. Multivariate analysis of overall survival by a Cox proportional hazards model.

\begin{tabular}{lll}
\hline Factor & HR $(95 \% \mathrm{CI})$ & $p$-Value \\
\hline $\begin{array}{l}\text { Smoking status } \\
\quad \text { Never smoked }\end{array}$ & 1.00 & \\
$\quad$ Current or former smoker & $1.30(0.69-2.48)$ & 0.418 \\
Driver mutation* & & \\
$\quad$ Yes & 1.00 & \\
$\quad$ No & $2.95(1.17-7.43)$ & 0.022 \\
Pretreatment & & \\
$\quad$ Yes & 1.00 & \\
$\quad$ No & $0.23(0.08-0.68)$ & 0.008 \\
CYFRA 21-1 & & \\
$\quad \leq 3.5 \mathrm{ng} / \mathrm{ml}$ & 1.00 & 0.007 \\
$\quad>3.5 \mathrm{ng} / \mathrm{ml}$ & $2.01(1.21-3.33)$ & \\
\hline
\end{tabular}

HR, Hazard ratio; CI, confidence interval; CYFRA 21-1, cytokeratin 19 fragment. *Epidermal growth factor receptor mutation or anaplastic lymphoma kinase translocation.

$(n=50)$ and those with normal $(n=25)$ levels of CYFRA 211 was 349 days $(95 \% \mathrm{CI}=263-425$ days) and 613 days $(95 \%$ $\mathrm{CI}=418-934$ days $)$, respectively $(p=0.009)$.

\section{Discussion}

This study showed that a high level of serum CYFRA 21-1 before initial chemotherapy was related to shorter PFS and OS, and a worse DCR with pemetrexed plus a platinumderivative therapy in patients with advanced nonSqNSCLC. The duration of OS correlated with serum CYFRA 21-1 levels in multivariate analysis, whether patients had driver mutations or not, and whether patients took pretreatment of EGFR-TKI or not. Considering the survival benefit of EGFR-TKI for patients with EGFR mutation, the serum CYFRA 21-1 level was the only factor by which the effectiveness of chemotherapy could be predicted in this study.

In previous meta-analysis, high pretreatment serum CYFRA 21-1 levels were related to shorter OS in patients with advanced-stage NSCLC, and the findings of the present study are consistent with $(5,6)$. However, regarding PFS, only one study has reported that the serum CYFRA 21-1 level predicted the duration of PFS in patients treated with carboplatin plus gemcitabine-treated for advanced NSCLC (10). Thus, it is not clear whether CYFRA 21-1 is only a factor predictive of antimetabolite-based chemotherapies, or whether it is also a predictive of various other regimens (e.g. taxanes or topoisomerase inhibitors). On the other hand, in patients operated on for early-stage NSCLC, a high preoperative serum CYFRA 21-1 level was associated with poor survival $(5,6)$. Considering that outcome, a high CYFRA level might lead to a worse outcome through tumor burden. Similarly, it is considered that a high tumor load leads to a worse outcome in patients with advanced-stage disease. However, the serum CEA level was not found to be related to survival in this study. These data suggest that not only tumor burden, but also tumor properties influence outcome.

Histological heterogeneity in lung cancer might also have an effect on outcome $(11,12)$. Pemetrexed treatment provides a better survival advantage for patients with tumors with a non-squamous histology than for those with a squamous histology (1). The fact that CYFRA 21-1 is a specific marker for squamous cell carcinoma $(13,14)$ suggests that elevated levels of serum CYFRA 21-1 indicate the presence of squamous cell components. For most patients with advanced NSCLC, histological classification of the tumor is based on a small biopsy or on cytological specimens. Pathogenic diagnosis of NSCLC based on a small biopsy has been shown to involve many false-positives/-negatives (15). In similar studies, it was reported that CYFRA 21-1 predicted the efficacy of EGFR-TKI treatment in patients with NSCLC harboring an EGFR mutation (16), and that patients whose tumors harbored an EGFR mutation with squamous histology had a shorter PFS (17). These data emphasize the importance of considering tumor heterogeneity in advanced lung cancer.

Our study has certain limitations. Firstly, not all patients with non-progressive disease in induction therapy underwent pemetrexed maintenance monotherapy. This may have influenced PFS and OS. Secondly, we adopted the upper limit of normal values at the two hospitals as the cut-off point for the serum tumor markers. However, these levels were decided from the viewpoint of diagnostic value. Therefore there may be better cut-off points for marker levels when considering predictive or prognostic value. Furthermore, it is expected that more effective therapeutic drugs for patients with high CYFRA 21-1 levels will be identified in the future. Other strategies, such as the addition of an anti-angiogenic inhibitor to pemetrexed-based chemotherapy or the use of an immunocheckpoint inhibitor, are considered worthy of consideration.

In conclusion, our study suggests that a high serum level of CYFRA 21-1 before treatment is a predictive and prognostic factor of therapy with pemetrexed combined with a platinum derivative therapy in patients with nonSqNSCLC.

\section{Acknowledgements}

The Authors thank Dr. Takefumi Kunieda for his assistance and stimulating discussions. 


\section{References}

1 Scagliotti G, Hanna N, Fossella F, Sugarman K, Blatter J, Peterson P, Simms L and Shepherd FA: The differential efficacy of pemetrexed according to nsclc histology: A review of two phase III studies. Oncologist 14(3): 253-263, 2009.

2 Scagliotti GV, Parikh P, von Pawel J, Biesma B, Vansteenkiste J, Manegold C, Serwatowski P, Gatzemeier U, Digumarti R, Zukin M, Lee JS, Mellemgaard A, Park K, Patil S, Rolski J, Goksel T, de Marinis F, Simms L, Sugarman KP and Gandara D: Phase III study comparing cisplatin plus gemcitabine with cisplatin plus pemetrexed in chemotherapy-naive patients with advanced-stage non-small-cell lung cancer. J Clin Oncol 26(21): 3543-3551, 2008.

3 Rodrigues-Pereira J, Kim JH, Magallanes M, Lee DH, Wang J, Ganju V, Martinez-Barrera L, Barraclough $\mathrm{H}$, van Kooten M and Orlando M: A randomized phase 3 trial comparing pemetrexed/carboplatin and docetaxel/carboplatin as first-line treatment for advanced, nonsquamous non-small cell lung cancer. J Thorac Oncol 6(11): 1907-1914, 2011.

4 Paz-Ares LG, de Marinis F, Dediu M, Thomas M, Pujol JL, Bidoli P, Molinier O, Sahoo TP, Laack E, Reck M, Corral J, Melemed S, John W, Chouaki N, Zimmermann AH, VisserenGrul C and Gridelli C: Paramount: Final overall survival results of the phase iii study of maintenance pemetrexed versus placebo immediately after induction treatment with pemetrexed plus cisplatin for advanced nonsquamous non-small-cell lung cancer. J Clin Oncol 31(23): 2895-2902, 2013

5 Xu Y, Xu L, Qiu M, Wang J, Zhou Q and Yin R: Prognostic value of serum cytokeratin 19 fragments (CYFRA 21-1) in patients with non-small cell lung cancer. Sci Rep 5: 9444, 2015.

6 Pujol JL, Molinier O, Ebert W, Daures JP, Barlesi F, Buccheri G, Paesmans M, Quoix E, Moro-Sibilot D, Szturmowicz M, Brechot JM, Muley T and Grenier J: Cyfra 21-1 is a prognostic determinant in non-small-cell lung cancer: Results of a metaanalysis in 2063 patients. Br J Cancer 90(11): 2097-2105, 2004

7 Fiala O, Pesek M, Finek J, Svaton M, Sorejs O, Bortlicek Z, Kucera $\mathrm{R}$ and Topolcan O: Prognostic significance of serum tumor markers in patients with advanced-stage NSCLC treated with pemetrexed-based chemotherapy. Anticancer Res 36(1): 461-466, 2016.

8 Eisenhauer EA, Therasse P, Bogaerts J, Schwartz LH, Sargent D, Ford R, Dancey J, Arbuck S, Gwyther S, Mooney M, Rubinstein L, Shankar L, Dodd L, Kaplan R, Lacombe D and Verweij J: New response evaluation criteria in solid tumours: Revised RECIST guideline (version 1.1). Eur J Cancer 45(2): 228-247, 2009.
9 Kanda Y: Investigation of the freely available easy-to-use software 'EZR' for medical statistics. Bone Marrow Transplant 48(3): 452-458, 2013

10 Edelman MJ, Hodgson L, Rosenblatt PY, Christenson RH, Vokes EE, Wang $X$ and Kratzke R: CYFRA $21-1$ as a prognostic and predictive marker in advanced non-small-cell lung cancer in a prospective trial: Calgb 150304. J Thorac Oncol 7(4): 649-654, 2012.

11 Roggli VL, Vollmer RT, Greenberg SD, McGavran MH, Spjut $\mathrm{HJ}$ and Yesner R: Lung cancer heterogeneity: A blinded and randomized study of 100 consecutive cases. Hum Pathol 16(6): 569-579, 1985 .

12 Travis WD, Rekhtman N, Riley GJ, Geisinger KR, Asamura H, Brambilla E, Garg K, Hirsch FR, Noguchi M, Powell CA, Rusch VW, Scagliotti $G$ and Yatabe Y: Pathologic diagnosis of advanced lung cancer based on small biopsies and cytology: A paradigm shift. J Thorac Oncol 5(4): 411-414, 2010.

13 Pujol JL, Grenier J, Daures JP, Daver A, Pujol H and Michel FB: Serum fragment of cytokeratin subunit 19 measured by CYFRA 21-1 immunoradiometric assay as a marker of lung cancer. Cancer Res 53(1): 61-66, 1993.

14 Kulpa J, Wojcik E, Reinfuss $M$ and Kolodziejski L: Carcinoembryonic antigen, squamous cell carcinoma antigen, CYFRA 21-1, and neuron-specific enolase in squamous cell lung cancer patients. Clin Chem 48(11): 1931-1937, 2002.

15 Cataluna JJ, Perpina M, Greses JV, Calvo V, Padilla JD and Paris F: Cell type accuracy of bronchial biopsy specimens in primary lung cancer. Chest 109(5): 1199-1203, 1996.

16 Tanaka K, Hata A, Kaji R, Fujita S, Otoshi T, Fujimoto D, Kawamura T, Tamai K, Takeshita J, Matsumoto T, Monden K, Nagata K, Otsuka K, Nakagawa A, Tachikawa R, Tomii K and Katakami N: Cytokeratin 19 fragment predicts the efficacy of epidermal growth factor receptor-tyrosine kinase inhibitor in non-small-cell lung cancer harboring EGFR mutation. J Thorac Oncol 8(7): 892-898, 2013.

17 Shukuya T, Takahashi T, Kaira R, Ono A, Nakamura Y, Tsuya A, Kenmotsu H, Naito T, Kaira K, Murakami H, Endo M, Takahashi $\mathrm{K}$ and Yamamoto N: Efficacy of gefitinib for nonadenocarcinoma non-small-cell lung cancer patients harboring epidermal growth factor receptor mutations: A pooled analysis of published reports. Cancer Sci 102(5): 1032-1037, 2011.

Received December 18, 2016

Revised January 26, 2017

Accepted January 27, 2017 